\title{
Distribution of high-risk HPV types among women in Sichuan province, China: a cross- sectional study
}

\author{
Lixia $\mathrm{He}^{1 *}$ and Junyong $\mathrm{He}^{2}$
}

\begin{abstract}
Background: Persistent infection with high-risk human papillomavirus (HR-HPV) is a major cause of cervical intraepithelial neoplasia and invasive cervical cancer. We investigated the prevalence of HR-HPV infection and distribution of viral genotypes among women in this area.

Methods: Women in Sichuan older than 20 years were screened for cervical cancer between January 2015 and December 2016 using liquid-based cytology testing and a flow cytometry-fluorescence hybridization test for HPVDNA. Frequency tables were evaluated using the chi-squared test $\left(x^{2}\right)$.

Results: Of the 17,319 women aged 20-85 years who participated in the study, Overall prevalence of HR-HPV infection was $12.6 \%(2178 / 17,319)$. The most prevalent viral type was HPV-52, which was present in $2.5 \%$ of individuals, followed by HPV-53 (1.6\%), HPV-58 (1.5\%), HPV-16 (1.1\%), HPV-56 (0.9\%), HPV-39 (0.8\%). In HSIL, the five most common HR-HPV types were HPV52, 16, 58,33 and 56. HPV16/18 in HSIL only makes up 25.9\% of HSIL, whereas HPV31/33/45/52/58 make up 56.8\%. Overall HR-HPV prevalence among women older than 65 years was 15. $2 \%$, significantly higher than the prevalence in other age groups $(P<0.05)$. Infection with dual or multiple HR-HPV types was associated with greater risk of abnormal cytology.

Conclusion: Overall HR-HPV prevalence in Sichuan is as high as in large cities in China. The HR-HPV types 52, 16, 58,33 and 56 predominated in this sample of HSIL women primarily from the banking and public sector in Sichuan. High prevalence among women older than 65 years needed pay attention to.
\end{abstract}

Keywords: Cervical cancer screening, Cytology, HPV-DNA test, Flow cytometry, Fluorescence hybridization

\section{Background}

Cervical cancer is one of the most common cancers among women worldwide, and nearly $90 \%$ of deaths from cervical cancer occur in developing countries [1]. In China, 130,000 new cases of cervical cancer are diagnosed annually, accounting for $28 \%$ of the world total, which likely reflects the integration of the Pap smear test into the Chinese healthcare system and its widespread acceptance by women. In 2015, cervical cancer was the second most common cancer among women aged 1545 years in China [2].

\footnotetext{
*Correspondence: hehelixia@163.com

'Shenzhen University General Hospital, Shenzhen University Clinical Medical Academy, Guangzhou, Guangdong, China

Full list of author information is available at the end of the article
}

Persistent infection with high-risk HPV (HR-HPV) is a major cause of cervical intraepithelial neoplasia and invasive cervical cancer [3-5], highlighting the need for a better understanding of infection epidemiology. While HR-HPV types 16 and 18 are responsible for approximately $70 \%$ of cervical cancer cases around the world [6], and vaccines against these types are effective $[7,8]$ and also available in China now, many other types of HR-HPV are circulating around the world, including HPV-26, 31, 33, 35, 39, 45, 51, 52, 53, 56, 58, 59, 66, 68, and 82 . These types differ greatly in their geographic distributions. For example, the five most common HR-HPV types in different regions of the world are as follows: South America, 16, 58, 18, 45, 31; North America, 16, 53, 18, 51, 31; Eastern Europe, 16, 31, 18, 66, 39; Southern Europe, 16, 66, 45, 31, 42; and Western Europe, 16,

(c) The Author(s). 2019 Open Access This article is distributed under the terms of the Creative Commons Attribution 4.0 International License (http://creativecommons.org/licenses/by/4.0/), which permits unrestricted use, distribution, and 
18, 31, 35, 33 [9-12]. Even within countries, type distributions can vary widely. Within China, the five most common virus types in Zhejiang province are 11, 16, 58, 52 , and 33 [13]; while the five most common in Guangdong province are 16, 52, 58, 18, and 45 [14]. Detailed understanding of HR-HPV type distribution can help inform vaccine research, development and allocation.

We are unaware of studies examining HR-HPV prevalence and genotype distribution among women in $\mathrm{Si}$ chuan province in China, so we undertook this large cross-sectional study.

\section{Methods}

\section{Study population}

The study was approved by the Hospital Ethics Committee of Sichuan University. Women from 17 cities of Sichuan province, with the highest proportions from Chengdu, Zigong, Panzhihua, Luzhou, Deyang, Mianyang, Guangyuan, Suining, Neijiang, Leshan, and Nanchong, were invited to participate in the study when they came to the Health Management Center of West China Hospital of Sichuan University for routine physical examinations between January 2015 and December 2016. Women were enrolled in the study if they were at least 20 years old, if they reported being sexually active, and if they provided written informed consent. Women were excluded from the study if they were pregnant or if they had a history of immunodeficiency disease, cervical cone or uterus resection, or acute genital inflammation. Pregnancy status and immunodeficiency history were assessed based on interviews and medical records.

\section{Cervical specimen collection}

Cervical cells were obtained from the cervical canal using two plastic brushes. One brush was placed into a 10-mL vial containing BD SurePath preservative fluid (TriPath Imaging, Burlington, NC, USA) for later cytology analysis. The other brush was placed into a 2-mL vial of preservation solution (Tellgen Life Science, Shanghai, China) for subsequent HPV-DNA testing. Samples for cytology were stored at room temperature for no more than 4 weeks, or at $4{ }^{\circ} \mathrm{C}$ for no more than 6 months. Samples for HPV-DNA tests were stored at room temperature for no more than 2 days, or at $2-8{ }^{\circ} \mathrm{C}$ for no more than 2 months.

\section{Liquid-based cytology}

Liquid-based cytology analysis was performed in the Pathology Department of West China Hospital of Sichuan University. Cytology specimens were evaluated independently by two experienced cytopathologists according to the 2001 Bethesda System [15]. Cytopathologists were blinded to the results of other assays. If the two experts came to different diagnoses, the cervical samples were reviewed again and a consensus diagnosis was obtained. The following diagnoses were possible: negative for intraepithelial lesion or malignancy (NILM), atypical squamous cells of undetermined significance (ASC-US), atypical squamous cells with the possibility of high-grade squamous intraepithelial lesion (ASC-H), low-grade squamous intraepithelial lesion (LSIL), high-grade squamous intraepithelial lesion (HSIL), squamous cervical cancer (SCC), atypical glandular cells (AGC), or adenocarcinoma in situ (AIS).

\section{HPV-DNA extraction and genotyping}

DNA was extracted using a commercial DNA Mini Kit (Tellgen Life Science) according to the manufacturer's instructions. DNA concentrations were determined using a NanoDrop1000 spectrophotometer, and samples were frozen at $-20^{\circ} \mathrm{C}$ until analysis.

HPV-DNA was detected using a flow cytometry-fluorescence hybridization technology that has been approved by the Chinese Food and Drug Administration for clinical use and has shown good diagnostic performance $[16,17]$. This assay uses nine sense primers (BSGP5+, $200 \mathrm{nM})$ and three antisense primers (5'-biotinylated-BSGP6+, $400 \mathrm{nM}$ ) to amplify a 150-bp fragment of the viral L1 open reading frame. At the same time, the assay contains primers MS3 and MS10 (300 nM) to amplify the $\beta$-globin gene as an internal control of DNA integrity. This assay can identify the following HR-HPV genotypes: $16,18,26,31,33,35,39,45,51,52,53,56$, $58,59,66,68$, and 82 . (It can also identify 10 low-risk HPV types.)

Oligonucleotide probes against each of the 17 HR-HPV types and 10 low-risk HPV types were synthesized with an amino group at the $5^{\prime}$ end. All PCR procedures were performed according to the manufacturer's recommendations. The mixture of PCR products and conjugate was incubated for $20 \mathrm{~min}$ at room temperature with shaking. After three washes in blocking solution, the beads were analyzed in a Luminex 200 reader (Luminex Corporation, TX, USA). This reader uses one laser to identify the bead type based on bead color, and a second laser to quantify reporter fluorescence on the bead. Median fluorescence intensity (MFI) for $\geq 100$ beads was measured [18-20].

MFI was used to stratify participants as having low or high HPV load based on calibration using plasmid standards from the World Health Organization Panel II [21] with $10^{2}$ and $10^{3}$ copies of $16 \mathrm{HPV}$ types per $100 \mathrm{ng}$ of human placental DNA. MFIs obtained with $10^{3} \mathrm{HPV}$ genome copies of the respective HPV types per $100 \mathrm{ng}$ of human placental DNA were used as cut-off values for classifying women as having low or high load of the respective HPV type. 


\section{Statistical analysis}

All analyses were performed using SPSS 19.0 for Windows (IBM, Armonk, NY). Prevalence of HR-HPV infection, genotype distribution, and single and multiple HPV infections were analyzed. Prevalence of $\operatorname{HR}-\mathrm{HPV}(\mathrm{n})=$ number of positive HR-HPV(n)/included objects. The significance of frequency distributions was evaluated using the chi-squared test $\left(X^{2}\right)$, and the associated $95 \%$ confidence intervals (CIs) were calculated using a binomial distribution analysis. For all analyses, $P<0.05$ was considered statistically significant.

\section{Results}

\section{Prevalence of HR-HPV infection}

A total of 17,319 women aged 20-85 years were included in this study. Their average age was $43.56 \pm$ 10.22 years and $80 \%$ were teachers, policewomen, government workers, bank workers, civil servants, or retirees; the type of employment and working/retired status were unknown for the remaining 20\%. All 27 HPV types that our HPV-DNA assay can detect were detected in this population, including the $17 \mathrm{HR}-\mathrm{HPV}$ types $16,18,26,31,33,35,39,45,51,52,53,56,58,59$, 66,68 , and 82 . The remaining 10 types belonged to low-risk HPV, which will not be discussed here.

Overall prevalence of HR-HPV infection was 12.6\% (2178/17,319). The most prevalent type was HPV-52, which was detected in 424 women, corresponding to an infection prevalence of $2.5 \%$. The next most prevalent types were 53 (1.6\%), 58 (1.5\%), 16 (1.1\%), 56 (0.9\%), 39
(0.8\%), 59 (0.7\%), $66(0.7 \%), 18(0.6 \%)$, and $51(0.6 \%)$ (Table 1). We divided these HR-HPV into three groups based on the HPV vaccine, the prevalence of HPV16/18 is $1.7 \%(300 / 17319)$, HPV $31 / 33 / 45 / 52 / 58$ is $4.71 \%$ ( $816 /$ 17319), HPV:26/35/39/51/53/56/59/66/68/82 is $6.1 \%$ (1062/17319).

The prevalence of HR-HPV infection was highest among women older than 65 years $15.2 \%$, followed by a prevalence of $13.5 \%$ among women aged $60-65$ and $11.2 \%$ among women aged 20-29 (Fig. 1). These percentages differed significantly $(P<0.05)$. Across all age groups, the 10 most frequent HR-HPV types were 52 , $53,58,16,18,59,66,51,39,56$ (Table 1), although the relative order of frequencies varied with age group. In different age groups, the prevalence of HPV:26/35/39/ $51 / 53 / 56 / 59 / 66 / 68 / 82$ is the highest, followed by HPV31/33/45/52/58, and then HPV16/18 (Fig. 2).

\section{Prevalence of infection with single, dual or multiple HR- HPV types among women of different age}

The prevalence of infection with a single HR-HPV type was $10.4 \%$ among women older than 65 , followed by $9.9 \%$ among women aged $60-65$, and $9.3 \%$ among women aged 20-29 or 50-59 (Fig. 1). The highest prevalence of dual HR-HPV infection was $3.3 \%$ among women older than 65 , $2.9 \%$ among women aged $60-65$, and $1.6 \%$ among women aged 20-29. The highest prevalence of multiple HR-HPV infection was $1.5 \%$ among women older than 65 , followed by $0.6 \%$ among women aged $60-65$, and lower rates among women aged $20-29$ or 50-59.

Table 1 Distribution of HR-HPV infections among women of different age ${ }^{\mathrm{a}}$

\begin{tabular}{|c|c|c|c|c|c|c|c|}
\hline HPV type & $20-29 y(\%) n=1361$ & $30-39 y(\%) n=4923$ & $40-49 y(\%) n=6227$ & $50-59 y(\%) n=3478$ & $60-65 y(\%) n=936$ & $>65 y(\%) n=394$ & Total $n=17,319$ \\
\hline 16 & $19(1.4)$ & $57(1.2)$ & $56(0.9)$ & $38(1.1)$ & $15(1.6)$ & $4(1.0)$ & $189(1.1)$ \\
\hline 18 & $12(0.9)$ & $25(0.5)$ & $40(0.6)$ & $17(0.5)$ & $11(1.2)$ & $6(1.5)$ & $111(0.6)$ \\
\hline 26 & $2(0.2)$ & $0(0.0)$ & $2(0.0)$ & $2(0.1)$ & $2(0.2)$ & $1(0.3)$ & $9(0.1)$ \\
\hline 31 & $4(0.3)$ & $7(0.1)$ & $13(0.2)$ & $5(0.1)$ & $2(0.2)$ & $0(0.0)$ & $31(0.2)$ \\
\hline 33 & $2(0.2)$ & $21(0.4)$ & $24(0.4)$ & $19(0.6)$ & $9(1.0)$ & $5(1.3)$ & $80(0.5)$ \\
\hline 35 & $5(0.4)$ & $15(0.3)$ & $23(0.4)$ & $13(0.4)$ & $5(0.5)$ & $2(0.5)$ & $63(0.4)$ \\
\hline 39 & $10(0.7)$ & $46(1.0)$ & $39(0.6)$ & $33(1.0)$ & $11(1.2)$ & $4(1.0)$ & $143(0.8)$ \\
\hline 45 & $2(0.2)$ & $9(0.1)$ & $9(0.1)$ & $6(0.2)$ & $1(0.1)$ & $3(0.8)$ & $27(0.2)$ \\
\hline 51 & $11(0.8)$ & $39(0.8)$ & $37(0.6)$ & $16(0.5)$ & $4(0.4)$ & $2(0.5)$ & $109(0.6)$ \\
\hline 52 & $39(2.9)$ & $120(2.4)$ & $143(2.3)$ & $85(2.4)$ & $30(3.2)$ & $7(1.8)$ & $424(2.5)$ \\
\hline 53 & $22(1.6)$ & $69(1.4)$ & $101(1.6)$ & $62(1.8)$ & $15(1.6)$ & $12(3.1)$ & $281(1.6)$ \\
\hline 56 & $8(0.6)$ & $36(0.7)$ & $49(0.8)$ & $30(0.9)$ & $13(1.4)$ & $11(2.8)$ & $147(0.9)$ \\
\hline 58 & $15(1.1)$ & $63(1.3)$ & $83(1.3)$ & $51(1.5)$ & $28(3.0)$ & $14(3.6)$ & $254(1.5)$ \\
\hline 59 & $11(0.8)$ & $25(0.5)$ & $42(0.7)$ & $28(0.8)$ & $10(1.1)$ & $7(1.8)$ & $123(0.7)$ \\
\hline 66 & $11(0.8)$ & $28(0.6)$ & $47(0.8)$ & $19(0.6)$ & $7(0.8)$ & $6(1.5)$ & $118(0.7)$ \\
\hline 68 & $6(0.4)$ & $6(0.1)$ & $7(0.1)$ & $8(0.2)$ & $1(0.1)$ & $4(1.0)$ & $32(0.2)$ \\
\hline 82 & $4(0.3)$ & $8(0.2)$ & $13(0.2)$ & $8(0.2)$ & $4(0.4)$ & $0(0.0)$ & $37(0.2)$ \\
\hline
\end{tabular}

${ }^{a}$ Values in the age columns refer to $\mathrm{n}$ (column\%) 


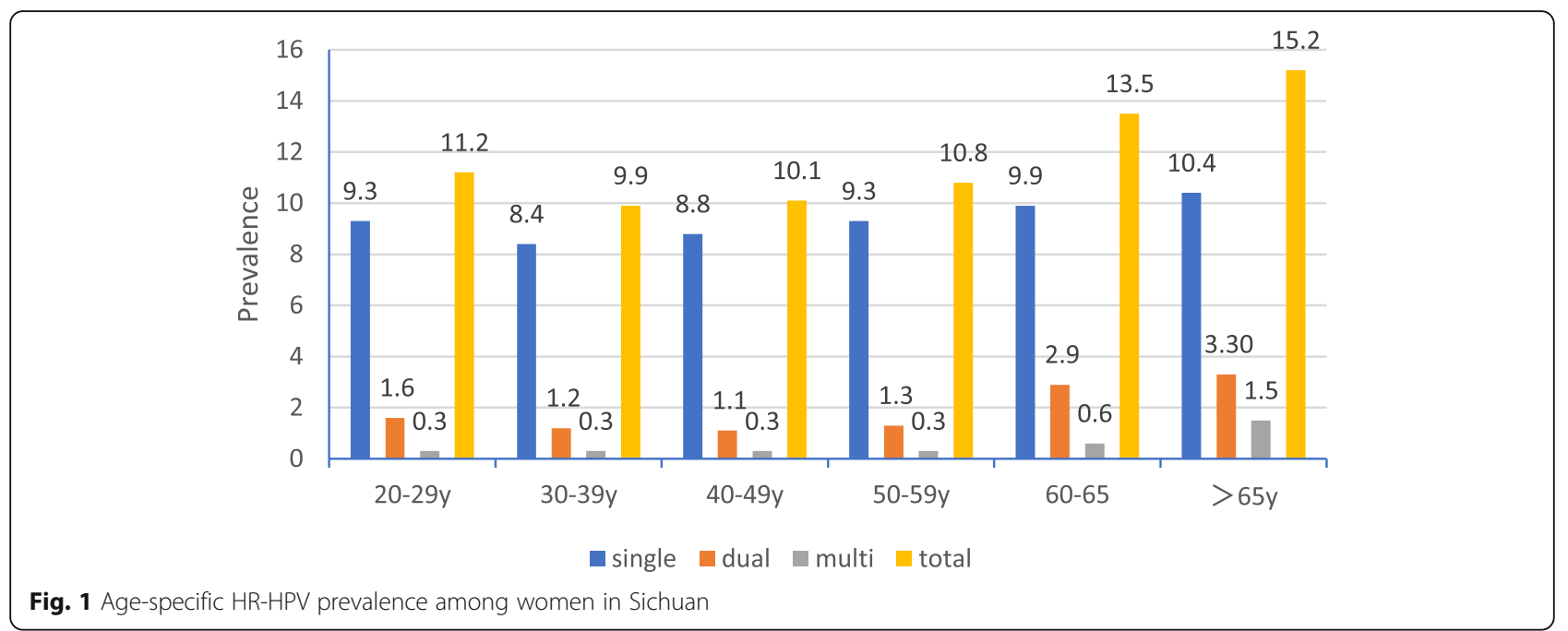

\section{Relationship between HR-HPV infection and cytology results}

As shown in Table 2, of the 17,319 samples, 97.2\% $(16,832 / 17319)$ were diagnosed as NILM and 2.8\% (487/ 17319) as abnormal cytology, comprising 1.1\% (192/ $17,319)$ with ASC-US, $1.0 \%(172 / 17,319)$ with LSIL, $0.5 \%$ $(81 / 17,319)$ with HSIL (including HSIL and ASC-H) and $0.2 \%(42 / 17,319)$ with AGC. The prevalence of HR-HPV infection among women diagnosed with NILM was $11.1 \%(1868 / 16,832)$, significantly lower than the prevalence among women diagnosed with abnormal cytology (63.7\%, 310/487, $P<0.05)$.

Except 1 case of HSIL caused by HPV26 combined with HPV16 infection, 10\% HPV33 infection leads to HSIL ranked NO.1, followed by HPV31(9.7\%), HPV16(9.5\%), HPV58(5.5\%), HPV52(4.7\%), HPV45(3.7\%).

The prevalence among women diagnosed with ASCUS was $31.8 \%$ (61/192); among women with LSIL, 61.6\%
(106/172); and among women with HSIL, 77.8\% (63/81). These percentages were significantly higher than the percentages among women diagnosed with NILM (9.5\%, $1596 / 16,832)$ or AGC $(2.4 \%, 1 / 42)$. No relationship was observed between AGC and HR-HPV infection. Different HR-HPV types predominated in different cytology groups, the five most frequent types among women with HSIL were 52, 16, 58, 33 and 56. In contrast, the five most frequent types among women with LSIL were 52 , $56,58,53$ and 16 . In the form that HPV16/18 only makes up $25.9 \%(21 / 81)$ of HSIL, whereas HPV31/33/45/52/58 make up 56.8\% (Table 3).

\section{Relationship between HR-HPV infection number and cytology results}

Compared with HR-HPV prevalence among the 16,832 cytologically normal participants, OR $(95 \% \mathrm{CI})$ was 3.6(2.6-5.2) in the ASCUS group, 13.1(9.4-18.3) in the

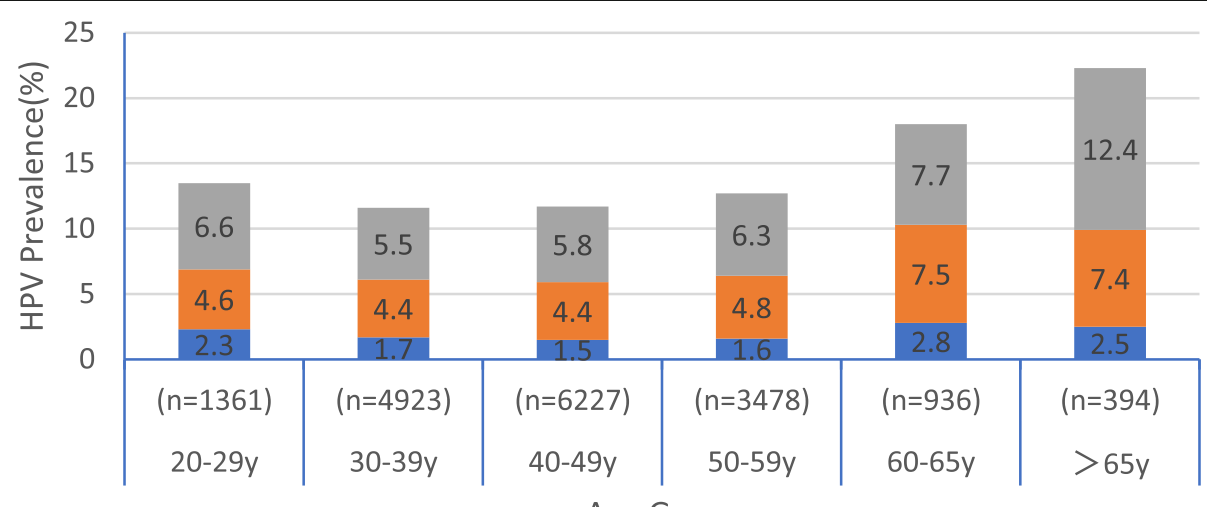

Age Group 
Table 2 Distribution of HR-HPV infections among women of different cytology

\begin{tabular}{|c|c|c|c|c|c|c|}
\hline HPV type & NILM, $\% n=16,832$ & ASCUS, $\% n=192$ & LSIL,\% $n=172$ & $\mathrm{HSIL}, \% n=81$ & $\mathrm{AGC}, \% n=42$ & Total $(n=17,319$ \\
\hline 16 & $154(81.5)$ & $6(3.2)$ & $11(5.8)$ & $18(9.5)$ & 0 & 189 (100\%) \\
\hline 18 & $93(83.8)$ & $6(5.4)$ & $8(7.2)$ & $3(2.7)$ & $1(0.9)$ & $111(100 \%)$ \\
\hline 26 & $8(88.9)$ & 0 & 0 & $1(11.1)$ & 0 & $9(100 \%)$ \\
\hline 31 & $23(74.2)$ & $2(6.5)$ & $3(9.7)$ & $3(9.7)$ & 0 & $31(100 \%)$ \\
\hline 33 & $56(70.0)$ & $7(8.8)$ & $9(11.3)$ & $8(10.0)$ & 0 & $80(100 \%)$ \\
\hline 35 & $52(82.5)$ & $3(4.8)$ & $6(9.5)$ & $2(3.2)$ & 0 & $63(100 \%)$ \\
\hline 39 & $136(95.1)$ & $0(0)$ & $6(4.2)$ & $1(0.7)$ & 0 & $143(100 \%)$ \\
\hline 45 & $25(92.6)$ & $0(0)$ & $1(3.7)$ & $1(3.7)$ & 0 & $27(100 \%)$ \\
\hline 51 & $96(88.1)$ & $4(3.7)$ & $7(6.4)$ & $2(1.8)$ & 0 & 109 (100\%) \\
\hline 52 & $351(82.8)$ & $24(5.7)$ & $28(6.6)$ & $20(4.7)$ & $1(0.2)$ & $424(100 \%)$ \\
\hline 53 & $259(92.2)$ & $5(1.8)$ & $14(5.0)$ & $3(1.1)$ & 0 & $281(100 \%)$ \\
\hline 56 & $122(83.0)$ & $4(2.7)$ & $17(11.6)$ & $4(2.7)$ & 0 & $147(100 \%)$ \\
\hline 58 & $211(83.1)$ & $12(4.7)$ & $17(6.7)$ & $14(5.5)$ & 0 & 254 (100\%) \\
\hline 59 & $114(92.7)$ & $3(2.4)$ & $4(3.3)$ & $2(1.6)$ & 0 & $123(100 \%)$ \\
\hline 66 & 108 (91.5) & $1(0.8)$ & $8(6.8)$ & $1(0.9)$ & 0 & 118 (100\%) \\
\hline 68 & $27(84.4)$ & $0(0)$ & $4(12.5)$ & $1(3.1)$ & 0 & 32 (100\%) \\
\hline 82 & $33(89.2)$ & $2(5.4)$ & $1(2.7)$ & $1(2.7)$ & 0 & 37 (100\%) \\
\hline
\end{tabular}

Values in the cytology rows refer to $\mathrm{n}$ (row\%)

LSIL group, and 27.7(16.0-48.0) in the HSIL group in the case of individuals with single HR-HPV infection. The corresponding results in the case of individuals with dual HR-HPV infection were 11.9(7.1-19.9, 24.92(14.742.4) and 76.95 (38.6-153.4). In the case of individuals with multiple HR-HPV infection, number of ASC was zero, OR (95\% CI) was $46.2(21.7-98.3)$ in the LSIL group, and $37.62(8.5-166.9)$ in the HSIL group. The wide $95 \%$ CIs in the HSIL group reflect the small number of such women in our sample. These results indicated that the severity of abnormal cytology in an infected individual increased with the number of HR-HPV types (Table 4).

\section{Discussion}

This is the first large study, to our knowledge, of HR-HPV prevalence among women in Sichuan province of China, and of the relationship between HR-HPV infection and abnormal cytology. In our sample of 17,319 women, primarily from the banking and public sectors, the overall rate of HR-HPV infection was $12.6 \%$, and the five most common types of HR-HPV were 52, 53, 58, 16 and 56. Our overall frequency of HR-HPV infection $(12.6 \%)$ is similar to frequencies reported for the large Chinese cities Tianjin (12.5\%) [22], Guangdong (7.3\%) [23], and Beijing (7.0\%) [24], but it is lower than the frequency reported for Shanghai (31.8\%) [25], Fujian (18.7\%) [26], Yunnan (18.4\%) [27], and Qingdao (32.2\%) [28]. Higher prevalence in some other studies may reflect that we recruited asymptomatic women who came to our center for routine physical check-ups rather than hospital patients, who may show higher HR-HPV prevalence. Discrepancies between our study and others may also reflect geographic or socioeconomic differences in virus prevalence. Further work should clarify to what extent these results are influenced by differences in demographics of the study samples and in virus testing methods.

In our study, the HR-HPV infection rates of the group aged over 60 is much higher, compared with other groups, which is similar to results of a study on women in Shenzhen, China [29]. A community-based survey of

Table 3 Prevalence of three HR-HPV groups according to different cytology results

\begin{tabular}{lllllll}
\hline HPV types & NILM & ASCUS & LSIL & HSIL & AGC & $\begin{array}{l}\text { Total } \\
(n=17,319)\end{array}$ \\
& $n=16,832$ & $n=192$ & $n=172$ & $n=81$ & $n=42$ & $1(2.4)$ \\
$31 / 33 / 45 / 52 / 58$ & $247(1.5)$ & $12(6.3)$ & $19(11.1)$ & $21(25.9)$ & $300(1.7)$ \\
$26 / 35 / 39 / 51 / 53 / 56 / 59 / 66 / 68 / 82$ & $666(4.0)$ & $45(23.4)$ & $58(33.7)$ & $46(56.8)$ & $1(2.4)$ & $816(4.7)$ \\
\hline
\end{tabular}

Values in the cytology columns refer to $\mathrm{n}$ (column\%) 
Table 4 Relationship between HR-HPV infection number and cytology results

\begin{tabular}{|c|c|c|c|c|c|}
\hline \multirow[t]{2}{*}{ No. HR-HPV } & \multicolumn{5}{|c|}{ Cytology diagnosis, n (column\%) } \\
\hline & NILM & ASCUS & LSIL & $\mathrm{HSIL}$ & AGC \\
\hline cases detected* & $(n=16,832)$ & $(n=192)$ & $(n=172)$ & $(n=81)$ & $(n=42)$ \\
\hline Negative & $15,236(90.5)$ & $131(68.2)$ & $66(38.4)$ & $18(22.2)$ & $41(97.6)$ \\
\hline Single & $1375(8.2)$ & $43(22.4)$ & $78(45.4)$ & $45(55.6)$ & 0 \\
\hline OR $(95 \% \mathrm{Cl})$ & 1 & $3.64(2.6-5.2)^{*}$ & $13.10(9.4-18.3)^{*}$ & $27.70(16.0-48.0)^{*}$ & \\
\hline Dual & $176(1.1)$ & $18(9.4)$ & $19(11.1)$ & $16(19.8)$ & $1(2.4)$ \\
\hline OR $(95 \% \mathrm{Cl})$ & 1 & $11.90(7.1-19.9)^{*}$ & $24.92(14.7-42.4)^{*}$ & $76.95(38.6-153.4)^{*}$ & $2.11(0.3-15.4)$ \\
\hline Multi & $45(0.3)$ & $0(0)$ & $9(5.2)$ & $2(2.5)$ & 0 \\
\hline OR $(95 \% \mathrm{Cl})$ & 1 & & $46.17(21.7-98.3)^{*}$ & $37.62(8.5-166.9)^{*}$ & \\
\hline
\end{tabular}

ORs were calculated relative to the Negative group. Trend test: ${ }^{*} p<0.05$

10,602 Taiwan women showed that HPV prevalence was highest in women aged 60-65 (20.1\%) [30]. A study consisting of 10,442 Fujian women showed that HPV prevalence showed a bi-modal trend with age [26]. A study of Shanghai women visiting a cervical disease diagnosis and treatment center showed an HR-HPV prevalence of $31.5 \%$ among women aged $\geq 65$, which was higher than in women aged 35-54 [25]. We speculate that because of the discomfort and embarrassment of gynecological examination, the participation rate of cervical cancer screening in the elderly is low, and most of the participants participate in the screening because of the discomfort symptoms of reproductive tract, so the positive rate is high. However, these results contrast with reports of declining infection rates with age in studies from Colombia, Japan [31, 32]. These discrepancies may reflect ethnic differences.

The most common HR-HPV types in Sichuan (52, 53, $58,16,56)$ appear to differ from those in other Chinese cities, such as Shanghai $(52,16,18,31,18)$ [25], Fujian $(16,52,58,18,53)$ [26], Tianjin $(16,18,58,66)$ [22], Guangdong $(52,58,16,18)[23]$ and Hunan $(16,52,58$, 18) [33].

Despite this geographic variation, this difference may be related to the included population. Some studies were patient specimens collected in the department of obstetrics and gynecology, while some were only targeted at the general population, and some were a combination of the two groups. The other potential reason for this discrepancy with other studies is due to the sample size, while our study included 17,319 women. It is worth mentioning that despite the high positive rate of HPV53, the cytological results of over 90\% HPV53 positive women were NILM.

We further analyzed the most common HPV genotype in HSIL. In this study, HPV types 52, 16, 58, 33 and 56 were the five most common HR-HPV types in HSIL. The first three most common HR-HPV types consisted with other studies in many cities in China. HPV-52 and
HPV-58 are also very common in Hong Kong and Taiwan [34, 35]. However, in our study, HPV16/18 only makes up 25.93\% of HSIL, whereas HPV31/33/45/52/58 make up $56.8 \%$. when we look at HPV prevalence in cancer, a meta-analysis showed that in cell-based detection, HPV16/58/18/52/33 were the five most frequently detected HR-HPV type in ICC in many studies, HPV31, 33,52 , and 58 were more frequent in CIN3 in comparison with cervicitis/normal samples, but less common in ICC [36]. The possible reason need further investigated.

Furthermore, we found that HR-HPV prevalence increased with severity of abnormal cytology, consistent with previous studies [22, 25-27]. This likely reflects the well-established association between HR-HPV and risk of cervical cancer. We further found that the presence of two or more HR-HPV types was associated with greater likelihood of abnormal cytology, also consistent with previous work [23, 37, 38]. This may be a virus load effect, though it may also reflect interaction between particular virus types. Further research should examine why multiple HR-HPV infection leads to greater risk of abnormal cytology.

Our epidemiological results on HR-HPV types in Sichuan province, with a female population of more than 40 million, may have immediate implications for Chinese public health practices. In 2017, the Chinese government approved vaccines effective against HPV16 and HPV-18, which together cause approximately $70 \%$ of cervical cancers around the world [6]. However, in this study, HPV16/18 only makes up $25.9 \%$ of HSIL, whereas HPV31/33/45/52/58 make up 56.8\%. Thus, the results indicate that bivalent HPV vaccine may fail to protect a substantial proportion of women from cervical intraepithelial neoplastic lesions and cervical cancer. This highlights the need for 9-valent human papillomavirus vaccine to cover this large group of vulnerable women.

Despite the large size and careful correlation between HR-HPV positivity and abnormal. 
cytology, our findings should be interpreted with caution in light of limitation. Our study involved primarily healthy, working women in urban, so the results may not be generalizable to remote rural female populations. However, a multicenter population-based study from Beijing, Shanghai, Shanxi, Henan and Xinjiang representing both urban and rural areas indicated that the HPV prevalence in CIN women from rural and urban have no significant difference [39]. In this study, we only analyzed the relationship between HPV and cytology, not histology. Cytology is also not as good as histology, as cytology is an imperfect test, we will further explore the relationship between HPV and histology in the next study.

Despite these limitations, our epidemiological study of HR-HPV in Sichuan province suggests that the substantial prevalence reported in several large Chinese cities may be true for a large section of the country. We also found that infection with multiple HPV types was associated with greater risk of abnormal cytology, which may help guide future studies into how HPV infection leads to cervical cancer.

\section{Conclusion}

The overall HR-HPV prevalence in Sichuan may be as high as in large cities in China. HR-HPV types 52, 53, 58,16 , and 56 predominate among infected women in Sichuan. Infection with two or more HR-HPV types may increase their risk of abnormal cytology. The high HR-HPV prevalence among the elder women deserve further attention.

\section{Abbreviations}

AGC: Atypical glandular cells; AIS: Adenocarcinoma in situ; ASC-H: Atypical squamous cells with the possibility of high-grade squamous intraepithelial lesion; ASC-US: Atypical squamous cells of undetermined significance; DNA: Deoxyribonucleic acid; HR-HPV: High-risk human papilloma virus; HSIL: High-grade squamous intraepithelial lesion; ICC: Invasive cervical cancer; LSIL: Low-grade squamous intraepithelial lesion; NILM: Negative for intraepithelial lesion or malignancy; PCR: Polymerase chain reaction; SCC: Squamous cervical cancer; STD: Sexually transmitted disease

\section{Acknowledgments}

We thank the nurses in the Health Management Center for their kind assistance in collecting data.

\section{Funding}

The Health and Family Planning Commission of Sichuan Province. Natural Science Fund of Shenzhen university.NO0000040560. The authors declare that the funding body did not take part in the design of the study; in data collection, analysis, or interpretation; or in writing the manuscript.

\section{Availability of data and materials}

The datasets used and analyzed in this study are available from the corresponding author on reasonable request.

\section{Authors' contributions}

LX He contributed substantially to designing the questionnaire, drafted and revised the article. JY He collect and analyzed data. Both authors read and approved the final manuscript.

\section{Ethics approval and consent to participate}

This study was approved by the Ethics Committee of Sichuan University. All participants provided written consent to take part in our study.

Consent for publication

Not applicable

\section{Competing interests}

The authors declare that they have no competing interests.

\section{Publisher's Note}

Springer Nature remains neutral with regard to jurisdictional claims in published maps and institutional affiliations.

\section{Author details}

${ }^{1}$ Shenzhen University General Hospital, Shenzhen University Clinical Medical Academy, Guangzhou, Guangdong, China. ${ }^{2}$ Health Management Center of West China Hospital of Sichuan University, Chengdu, Sichuan, China.

Received: 5 November 2018 Accepted: 26 April 2019

Published online: 08 May 2019

\section{References}

1. Torre LA, Bray F, Siegel RL, Ferlay J, Lortet-Tieulent J, Jemal A. Global cancer statistics, 2012. CA Cancer J Clin. 2015;65:87-108

2. Chen WQ, Zheng RS, Baade PD, et al. Cancer statistics in China, 2015. CA Cancer J Clin. 2016;0:1-18.

3. Munoz N, Bosch FX, de Sanjose $\mathrm{S}$, et al. The causal link between human papillomavirus and invasive cervical cancer: a population-based casecontrol study in Colombia and Spain. Int J Cancer. 1992;52:743-9.

4. Schiffman MH, Bauer HM, Hoover RN, et al. Epidemiologic evidence showing that human papillomavirus infection causes most cervical intraepithelial neoplasia. J Natl Cancer Inst. 1993:85:958-64.

5. Walboomers JM, Jacobs MV, Manos MM, et al. Human papillomavirus is a necessary cause of invasive cervical cancer worldwide. J Pathol. 1999; 189:12-9

6. Ramakrishnan S, Partricia S, Mathan G. Overview of high-risk HPV's 16 and 18 infected cervical cancer: pathogenesis to prevention. Biomed Pharmacother. 2015;70:103-10.

7. FUTURE II Study Group. Quadrivalent vaccine against human papillomavirus to prevent high-grade cervical lesions. N Engl J Med. 2007;356(19):1915-27.

8. Paavonen J, Naud P, Salmerón J, et al. Efficacy of human papillomavirus (HPV)-16/18 AS04-adjuvanted vaccine against cervical infection and precancer caused by oncogenic HPV types (PATRICIA): final analysis of a double-blind, randomised study in young women. Lancet. 2009;374(9686): 301-14.

9. AlObaid A, Al-Badawi IA, Al-Kadri H, Gopala K, Kandeil W, Quint W, et al. Human papillomavirus prevalence and type distribution among women attending routine gynecological examinations in Saudi Arabia. BMC Infect Dis. 2014;14:643.

10. Zhang HY, Fei MD, Jiang Y, Fei QY, Qian $H$, Xu L, et al. The diversity of human papillomavirus infection among human immunodeficiency virusinfected women in Yunnan, China. Virol J. 2014;11:202.

11. Moosa K, Alsayyad AS, Quint W, Gopala K, De Antonio R. An epidemiological study assessing the prevalence of human papillomavirus types in women in the Kingdom of Bahrain. BMC Cancer. 2014;14:905.

12. de Sanjose S, Diaz M, Castellsaque X, Clifford G, Bruni L, Munoz N, Bosch FX. Worldwide prevalence and genotype distribution of cervical human papillomavirus DNA in women with normal cytology: a meta-analysis Lancet Infect Dis. 2007;7:453-9.

13. Liu X, Fan X, Yu Y, Ji L, Yan J, Sun A. Human papillomavirus prevalence and type-distribution among women in Zhejiang Province, Southeast China: a cross-sectional study. BMC Infect Dis. 2014:14:708.

14. Jing L, Zhong X, Zhong Z, Huang W, Liu Y, Yang G, Zhang X, Zou J, Jing C, Wei X. Prevalence of human papillomavirus infection in Guangdong Province, China: a population-based survey of 78,355 women. Sex Transm Dis. 2014:41:732-8.

15. Solomon D, Davey D, Kurman R, Moriarty A, O'Connor D, Prey M, Raab S, Sherman M, Wilbur D, Wright TJ, Young N. The 2001 Bethesda system: terminology for reporting results of cervical cytology. JAMA. 2002;287:2114-9. 
16. Tang YS, Zheng L, Yang SS, Li B, Su HT, Zhang LP. Epidemiology and genotype distribution of human papillomavirus (HPV) in Southwest China: a cross-sectional five years study in non-vaccinated women [J]. Virol J. 2017; 14:84-94.

17. Li K, Yin R, Li Q, Wang DQ. Analysis of HPV distribution in patients with cervical precancerous lesions in Western China [J]. Medicine. 2017;96(29): e7304.

18. Schmitt M, Bravo I, Snijders P, Gissmann L, Pawlita M, Waterboer T. Beadbased multiplex genotyping of human papillomaviruses. J Clin Microbiol. 2006;44:504-12.

19. Dunbar SA, Vander Zee CA, Oliver KG, Karem KL, Jacobson JW. Quantitative, multiplexed detection of bacterial pathogens: DNA and protein applications of the luminex LabMAP system. J Microbiol Methods. 2003;53:245-52.

20. Louie KS, de Sanjose S, Diaz M, et al. Early age at first sexual intercourse and early pregnancy are risk factors for cervical cancer in developing countries. Br J Cancer. 2009;100:1191-7.

21. Eklund C, Zhou T, Dillner J. For the WHO human papillomavirus laboratory network. Global proficiency study of human papillomavirus genotyping. J Clin Microbiol. 2010:48:4147-55.

22. Chen X, Wallin K-L, Duan M, Gharizadeh B, Zheng B, Qu P. Prevalence and genotype distribution of cervical human papillomavirus (HPV) among women in urban Tianjin, China. J Med Virol. 2015;87:1966-72.

23. Jing $L$, Zhong $X$, Huang W, Liu $Y$, et al. HPV genotypes and associated cervical cytological abnormalities in women from the Pearl River Delta region of Guangdong Province, China: a cross-sectional study. BMC Infect Dis. 2014;14:388.

24. Zhang D, Li T, Chen L, Zhang X, Zhao G, Liu Z. Epidemiological investigation of the relationship between common lower genital tract infections and high-risk human papillomavirus infections among women in Beijing, China. PLoS One. 2017;12(5):e0178033.

25. Singh S, Zhou Q, Yu Y, Xu X, Huang X, Zhao J, Han L, Wang K, Sun J, Li F. Distribution of HPV genotypes in Shanghai women. Int J Clin Exp Pathol. 2015;8(9):11901-8.

26. Sun PM, Song YY, Ruan GY, Mao XD, Kang YF, Dong BH, Lin F. Clinical validation of the PCR-reverse dot blot human papillomavirus genotyping test in cervical lesions from Chinese women in the Fujian province: a hospital-based population study. J Gynecol Oncol. 2017;28(5):e50.

27. Baloch Z, Yuan T, Wang B, et al. Ethnic and geographic variations in HPV prevalence and genotype distribution in North-Western Yunnan, China [J]. J Med Virol. 2016;88(3):532-40

28. Bi Q, Zhang L, Zhao Z, et al. Human papillomavirus prevalence and genotypes distribution among female outpatients in Qingdao, East China [J]. J Med Virol. 2015;87(12):2114-21.

29. He GR, Wu XC. Analysis of the genotyping human papillomavirus from Shenzhen women. J Modern Lab Med. 2007:02:24-6.

30. Chen HC, You SL, Hsieh CY, et al. Prevalence of genotype-specific human papillomavirus infection and cervical neoplasia in Taiwan: A communitybased survey of 10,602 women. Int J Cancer. 2011;128(5):1192-1203.

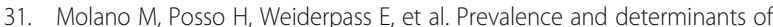
HPV infection among Colombian women with normal cytology. Br J Cancer 2002;87:324-33.

32. Inoue M, Sakaguchi J, Sasagawa T, Tango M. The evaluation of human papillomavirus DNA testing in primary screening for cervical lesions in a large Japanese population. Int J Gynecol Cancer. 2006;16:1007-13.

33. Li H-T, Zhang J, Chen Z-D, Zhou B, Tan Y. Prevalence of human papillomavirus genotypes among women in Hunan province, China European journal of obstetrics \&gynecology and reproductive biology, vol. 70; 2013. p. 202-5

34. Carvalho MO, Almeida RW, Leite FM, et al. Detection of human papillomavirus DNA by the hybrid capture assay. Braz J Infect Dis. 2003;7: 121-5.

35. Lin H, Ma YY, Moh JS, et al. High prevalence of genital human papillomavirus type 52 and 58 infection in women attending gynecologic practitioners in South Taiwan. Gynecol Oncol. 2006;101:40-5.

36. Xu H-H, Wang K, Feng X-J, Dong S-S, Lin A-F, Zheng L-Z, et al. Prevalence of human papillomavirus genotypes and relative risk of cervical cancer in China: a systematic review and meta-analysis. Oncotarget. 2018;9:15386-97.

37. Brebi P, Ili CG, Andana A, Menzel D, Lopez J, Guzman P, Melo A, Buchegger $K$, Roa JC. Frequency of human papillomavirus in women attending cervical cancer screening program in Chile. BMC Cancer. 2017:17:518.
38. Wheeler CM, Hunt WC, Cuzick J, Langsfeld E, Pearse A, Montoya GD, Robertson M, Shearman CA, Castle PE. A population-based study of human papillomavirus genotype prevalence in the United States: baseline measures prior to mass human papillomavirus vaccination. Int J Cancer. 2013;132:198207.

39. Zhang R, Velicer C, Chen W, Liaw KL, Wu EQ, Liu B, Cui JF, Belinson JL, Zhang X, Shen GH. Human papillomavirus genotype distribution in cervical intraepithelial neoplasia grades 1 or worse among 4215 Chinese women in a population-based study. Cancer Epidemiol. 2013;37:939-45.

\section{Ready to submit your research? Choose BMC and benefit from:}

- fast, convenient online submission

- thorough peer review by experienced researchers in your field

- rapid publication on acceptance

- support for research data, including large and complex data types

- gold Open Access which fosters wider collaboration and increased citations

- maximum visibility for your research: over $100 \mathrm{M}$ website views per year

At $\mathrm{BMC}$, research is always in progress.

Learn more biomedcentral.com/submissions 